\title{
Decolourisation and Detoxification of Reactive Azo Dyes by Saccharothrix Aerocolonigenes TE5
}

\author{
Rizwana Parvez S., Uma Maheswari Devi Palempalle* \\ Department of Applied Microbiology, Sri Padmavati Mahila Visvavidyalayam, Tirupati, Andhra Pradesh, India \\ *Corresponding author: umadevi66@yahoo.co.in \\ Received May 05, 2015; Revised May 19, 2015; Accepted July 21, 2015
}

\begin{abstract}
Reactive azo dyes primarily present in the effluent of textile industries are recalcitrant molecules and are highly toxic enough to impart severe adverse effects on vital organs of human or animal system and are difficult to degrade by biological means. The present study is structured to study the decolourization and detoxification potential of Saccharothrix aerocolonigenes strain TE5 isolated from the soil contaminated with textile effluents. The percent of decolourization was calculated under static and shaking conditions by employing UV-VIS Spectroscopy. The effect of $\mathrm{pH}$, temperature, carbon and nitrogen sources on the rate of decolourization was determined. The toxicity of the degraded products was assessed by germination assay.
\end{abstract}

Keywords: azo dyes, textile effluents, actinomycetes, degradation, phytotoxic analysis

Cite This Article: Rizwana Parvez S., and Uma Maheswari Devi Palempalle, "Decolourisation and Detoxification of Reactive Azo Dyes by Saccharothrix Aerocolonigenes TE5." Journal of Applied \& Environmental Microbiology, vol. 3, no. 2 (2015): 58-62. doi: 10.12691/jaem-3-2-5.

\section{Introduction}

The textile industry is rated as one of the most prominent polluting industry among all the industrial sectors based on the volume and composition of dyes released in to the water stream [1,2]. Globally, the total organic dye production is found to be more than 100,000 tons/year [3]. The textile effluents have notable features with reference to $\mathrm{pH}$ profile, amount of dissolved oxygen, organic and inorganic chemical complexes [4]. Release of textile dyes in to water bodies causes an unpleasant appearance by imparting colour/odor and also the breakdown products of textile dyes are highly toxic that involves in the process of mutagesis and carcinogenesis [5]. During the dying process, a sizable amount of dye is lost in the effluent waste water and the loss was reported of about $10-15 \%$ of total dyes [6].

The textile dyes are catergorised as azo, cationic, basic, anthraquinone and metal complex dyes based on the nature of their chemical structure [7]. Azo dyes, which represent about one-half of all other dyes which are commonly engaged as colouring agents in textile industry. The reactive azo dyes are extensively used in textile industry due to their unique characteristics such as brilliant colour band, diverse colour shades, waterfastness profile and easy application technique with low energy consumption [8]. The release of azo dyes into the surrounding environment causes serious damage as they intensely affect the photosynthetic activity of hydrophytes by limiting the light penetration and their breakdown products will lead into acute toxicity of ecosystems. The azo groups are generally connected to aromatic heterocyclic or aliphatic groups and these side chains are necessary for imparting the colour of the dye [9]. Azo dyes are resistant to degradation and remains persistent for long time due to their fused aromatic structure [10]. By keeping in view the importance of azo dyes, the present study is designed to evaluate the potential of saccharothrix aerocolonigenes strain TE5, a terrestrial actinomycetes, isolated from the soil sample contaminated by textile effluent.

\section{Materials and Methods}

\subsection{Dyes}

Azo dyes - namely Reactive Red 1 (RR1), Reactive Orange 107 (RY107) and Reactive black 5 (RB5) are collected from Madanapalle town, Chittoor district, Andhra Pradesh, India.

\subsection{Preparation of Dye Stock Solution}

The stock solution of the three dyes was prepared by dissolving $2.0 \mathrm{~g}$ in $10 \mathrm{ml}$ distilled water $(200 \mathrm{mg} / \mathrm{m} 1)$ and sterilized by autoclaving at $120^{\circ} \mathrm{C}$ for 30 minutes.

\subsection{Microorganisms and Culture Media}

The isolate was designated as Saccharothrix aerocolonigenes strain TE5 based on the biochemical and molecular characterization (data not shown) and was maintained on Glucose malt extract (Glucose 4g; Yeast extract 4g; Malt extract 10g; CaCO3 2g; Distilled water $1000 \mathrm{ml}$ ) and preserved for further use.

\subsection{Decolourisation Assay}


Typical decolourization experiments were carried out in $250 \mathrm{ml}$ conical flasks with $100 \mathrm{ml}$ volumes of a sterile Mineral salt medium. Saccharothrix aerocolonigenes strain TE5 was inoculated into mineral medium containing 600 ppm of one of the dye such as RR1, RY107 or RB5 and incubated at $37^{\circ} \mathrm{C}$ both under static and shaking conditions. Control was maintained without the inoculum. Three independent experiments were conducted for the selected azo dyes. All samples were collected at regular intervals, centrifuged at $10000 \mathrm{~g}$ for $10 \mathrm{~min}$ and the supernatant was used for measuring absorption at $410 \eta \mathrm{m}$ for RY-107 and 540ๆm for RR1 or RB5 using UV-VIS spectrophotometer. The percent decolourization of reactive azo dyes was determined [11].

\subsection{Decolourization at Different Temperatures}

In order to determine the optimum temperature for the decolourization of the azo dyes, the test tubes with minimal broth were inoculated with $0.1 \mathrm{ml}$ of overnight cultures and incubated at different temperatures ranging from $4^{\circ} \mathrm{C}$ to $45^{\circ} \mathrm{C}$ for $48 \mathrm{~h}$. At the end of incubation period, the magnitude of decolourization of the reactive dyes was measured and optimum temperature was recorded.

\subsection{Effect of pH on Decolourisation}

The ability of the isolate to decolourise the azo dyes at $\mathrm{pH}$ ranging from $3-9$ was tested in minimal broth by keeping other conditions as constant (dye concentration $600 \mathrm{mg} / \mathrm{L}$, temperature $37^{\circ} \mathrm{C}$. The percent of decolourization was measured after $24 \mathrm{~h}$.

\subsection{Effect of Carbon on Decolourisation}

The Mineral Salt Medium containing 600 ppm of dye was supplemented with carbon sources (1\%) such Glucose, Lactose and Sucrose to determine their effect on the degradation potential of Saccharothrix aerocolonigenes strain TE5. The experiments with individual dye were performed at $\mathrm{pH} 7$ and temperature $37^{\circ} \mathrm{C}$ for $24 \mathrm{~h}$.

\subsection{Effect of Nitrogen on Decolourization}

To determine the effect of Nitrogen sources on decolourisation, the medium was augmented with 1\% Nitrogen sources (Peptone, Beef extract and Yeast Extract) and was inoculated with Saccharothrix aerocolonigenes strain TE5 at $37^{\circ} \mathrm{C}$ for $24 \mathrm{~h}$. At the end of incubation, the percent of decolurisation was estimated.

\subsection{Bioassy for Phytotoxicity}

The phytotoxic nature of the degraded azo dye was studied by seed germination assay. The tolerance level of the wheat and green gram towards the toxicity of the RR1dye and RY107 respectively and their degraded products were observed. The Saccharothrix aerocolonigenes TE5 culture was inoculated to the Mineral Salt Medium containing 600ppm of Dye RR1 and incubated at $37^{\circ} \mathrm{C}$ for 48h. After degradation of the dye, the culture was harvested and centrifuged at 10,000 rpm for 10 minutes and supernatant was collected. The seeds of both wheat and green gram were soaked either in the decolourised supernatant or original dye (600 mg/l). The seeds wet with the distilled water were taken as the control. After overnight period, the soaked seeds were placed on the paper towels for germination [12]. Germination was continuously monitored for 7days. The perncentage of germination, the length of plumule and radical of the germinated seeds was measured after 7 days and the results were tabulated.

\subsection{Statistical Analysis}

The results obtained during experimentation were expressed in terms of Means and Standard Error (SE). Data was defined statistically by ANOVA (Single factor), T-test. Correlation between different parameters was calculated by SPSS software. Probability (p-value) less than 0.05 and 0.01 was considered significant and highly significant respectively.

\section{Results and Discussion}

The Saccharothrix aerocolonigenes TE5 was employed for the degradation of the three reactive azo dyes. From the present study, it was found that Saccharothrix aerocolonigenes TE5 could decolourize the reactive azo dyes significantly within 48h. The efficacy of decolourisation depends upon the adaptability and survival of these microorganisms during the degradation processes [13]. As shown in Figure 1, the Saccharothrix aerocolonigenes TE5 decolourized RR1 (92\%), RY 107 (90\%) and RB (54\%) from the MSM medium after 48h of incubation under static conditions whereas, the percentage of decolourization was reduced from $92 \%$ to $62 \%$ for RR1, from $90 \%$ to $74 \%$ for RY 107 and from $54 \%$ to $41 \%$ for RB5 under shaking conditions (Figure 2).

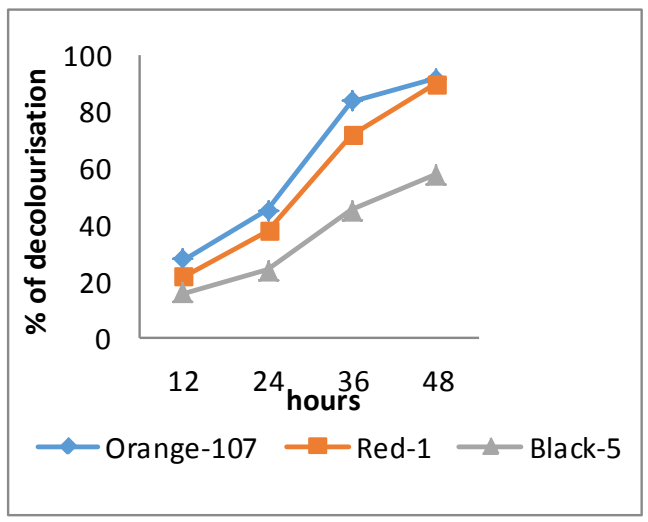

Figure 1. Decolourisation of Reactive azo dyes by Saccarothrix aerocolonigenes TE5 under static conditions. The data indicate the mean of three independent experiments Mean \pm SEM. $\mathrm{p}<0.001$

Initially, the effect of $\mathrm{pH}$ on the decolourization of reactive dyes was studied at a $\mathrm{pH}$ range of 3.0-9.0. The Saccharothrix aerocolonigenes TE5 was capable of decolorizing all the three reactive dyes and it showed maximum decolourisation of $92 \%$ for RR1 and $80 \%$ for RY107 and for 52\% with RB5 at pH 7.0 (Figure 3). The degradation percentage was observed to be higher with RY 107 when compared with RR1 and RB5. The optimum $\mathrm{pH}$ for decolourization was found to be 7.0 and decrease in decolourisation was noticed both at acidic as well as basic $\mathrm{pH}$ range. The enzymatic reduction of the azo bond resulted into the formation of aromatic amines which in turn increases the $\mathrm{pH}$ of the medium while comparing with original azo compound [14]. This indicates the 
absence of aromatic amines in the degraded samples of these three dyes. As per the data shown in Figure 4, the optimum temperature was found to be $37^{\circ} \mathrm{C}$ for effective decolourisation of the selected reactive dyes. The decline in colour removal activity at higher temperatures can be attributed to the loss of cell viability or due to the denaturation of an azo reductase or laccase enzyme $[15,16]$.

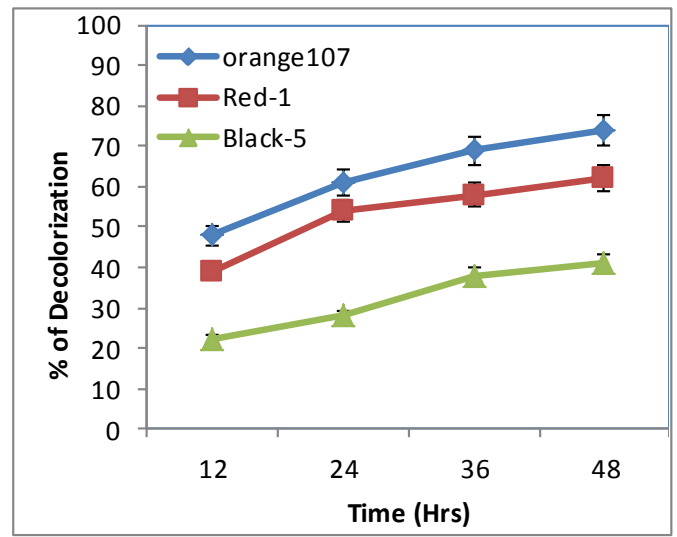

Figure 2. Decolourisation of Reactive azo dyes by Saccarothrix aerocolonigenes TE5 under shaking conditions. The data indicate the mean of three independent experiments Mean \pm SEM. $\mathrm{p}<0.05$

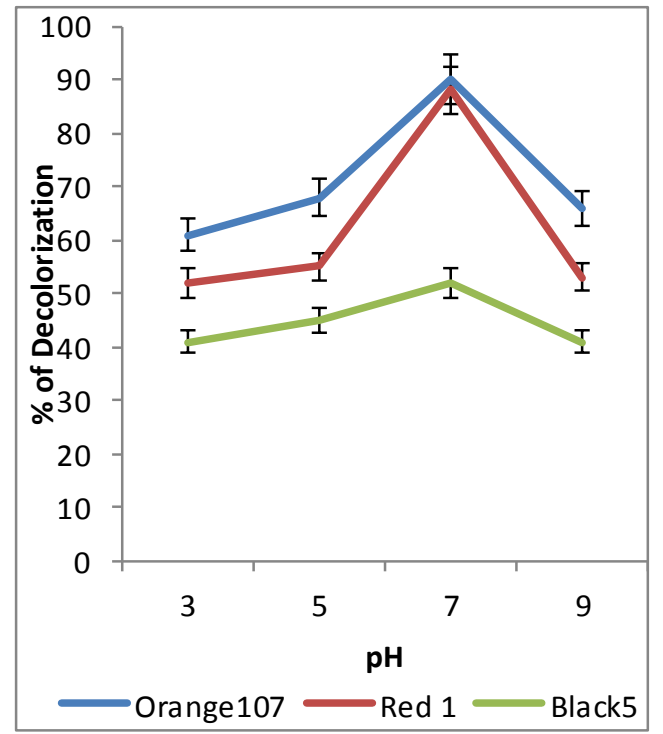

Figure 3. The effect of pH on the decolurization of of three reactive azo dyes by Saccarothrix aerocolonigenes TE5. The data indicates the mean of three independent experiments Mean \pm SEM. $p<0.01$

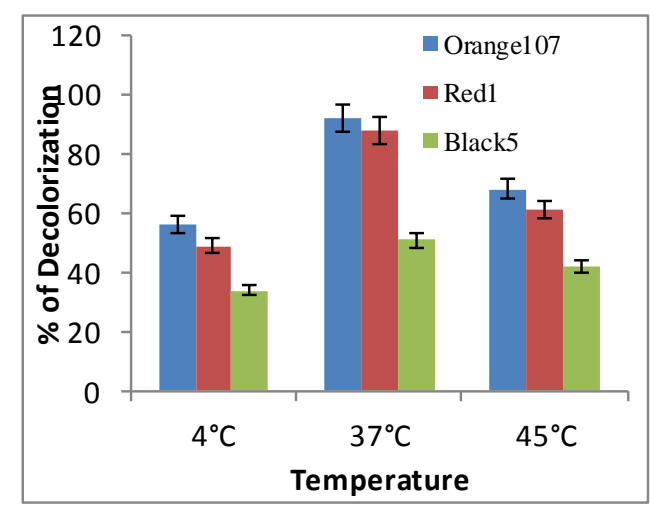

Figure 4. The effect of temperatue on the decolurization of of three reactive azo dyes by Saccarothrix aerocolonigenes TE5. The data indicates the mean of three independent experiments Mean \pm SEM. $\mathrm{p}<0.01$

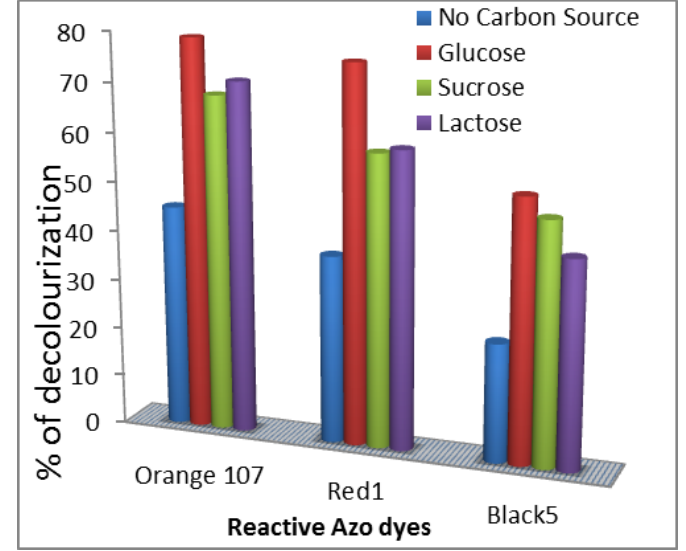

Figure 5. The effect of Carbon sources on the colour removal of three reactive azo dyes by Saccarothrix aerocolonigenes TE5. The data indicate the mean of three independent experiments Mean \pm SEM. $\mathrm{p}<0.01$

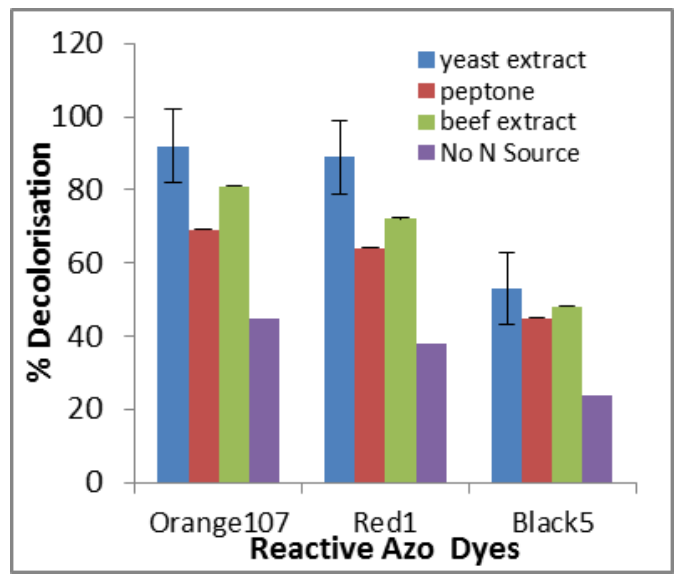

Figure 6. The effect of Nitrogen sources on the colour removal of three reactive azo dyes by Saccarothrix aerocolonigenes TE5. The data indicate the mean of three independent experiments Mean \pm SEM. $p<0.01$

The decolourization of reactive azo dyes was studied in the presence of carbon and nitrogen additives. The carbon sources such as glucose, fructose and sucrose at $1 \%$ were used as co-substrates to investigate their effects on dye decolourization after 24h of incubation with Saccharothrix aerocolonigenes TE5. The culture media supplemented with additional source of glucose exhibited two fold increase in the decolourisation of all three reactive dyes on comparison with sucrose and lactose (Figure 5). The literature reported the correlative influence of glucose concentration on the decolorization of various dyes [17]. The effect of different nitrogen sources on the decolourization of selected reactive azo dyes was studied by addition of $1 \%$ nitrogen source to Mineral salt medium and incubating with Saccharothrix aerocolonigenes TE5 for 24h. The medium supplemented with beef extract, yeast extract and peptone showed significant effect on the degradation of the dyes RR1, RY107 and RB5. Among nitrogen sources, the degradation was observed to be high with yeast extract than other nitrogen sources (Figure 6). The decolourization of reactive brilliant blue by Rhodocyclus gelatinosus XL-1 significantly increased with the addition of peptone to the reaction medium.

Seed germination assay and plant growth bioassay are the most common methods used to evaluate the toxic nature of the decolourised dyes [18]. Thus, in the present study, the phytotoxicity of the dye and its metabolites 
after degradation by Saccharothrix aerocolonigenes TE5 was observed (Table 1).

Table 1. Effect of degraded and parent RR1 dye on the germination of wheat and bean seedlings

\begin{tabular}{|c|c|c|c|c|c|c|c|c|c|}
\hline \multirow{2}{*}{ Seed } & \multirow{2}{*}{ Sample } & \multicolumn{6}{|c|}{ Percentage of Germination } & \multirow[t]{2}{*}{$\begin{array}{l}\text { Average shoot } \\
\text { length }(\mathrm{cm})^{*}\end{array}$} & \multirow[t]{2}{*}{$\begin{array}{l}\text { Average root Length } \\
(\mathrm{cm})\end{array}$} \\
\hline & & $\begin{array}{c}\text { Day- } \\
2 \\
\end{array}$ & $\begin{array}{c}\text { Day- } \\
3 \\
\end{array}$ & $\begin{array}{c}\text { Day- } \\
4 \\
\end{array}$ & $\begin{array}{c}\text { Day- } \\
5 \\
\end{array}$ & $\begin{array}{c}\text { Day- } \\
6 \\
\end{array}$ & $\begin{array}{c}\text { Day- } \\
7 \\
\end{array}$ & & \\
\hline \multirow{3}{*}{ wheat } & D. water & 12 & 28 & 48 & 76 & 89 & 99 & $9.5 \pm 0.3$ & $3.2 \pm 0.2$ \\
\hline & Treated dye & 7 & 22 & 31 & 46 & 67 & 70 & $5.6 \pm 0.4$ & $2.2 \pm 0.5$ \\
\hline & Untreated dye & - & 10 & 15 & 17 & 20 & 20 & $1.8 \pm 0.2$ & $0.9 \pm 0.31$ \\
\hline \multirow{3}{*}{ Green gram } & D. water & 20 & 32 & 58 & 86 & 98 & 100 & $8.7 \pm 0.11$ & $2.9 \pm 0.4$ \\
\hline & Treated dye & 8 & 28 & 39 & 59 & 67 & 72 & $4.9 \pm 0.43$ & $2.00 \pm 0.2$ \\
\hline & Untreated dye & 4 & 13 & 17 & 25 & 26 & 26 & $1.4 \pm 0.25$ & $0.8 \pm 0.32$ \\
\hline
\end{tabular}

The seedlings of Triticum aestivum showed 3.5 fold (70\%) germination rate with degraded RR1sample on comparison with RR1 control dye (20\%) (Figure 7).

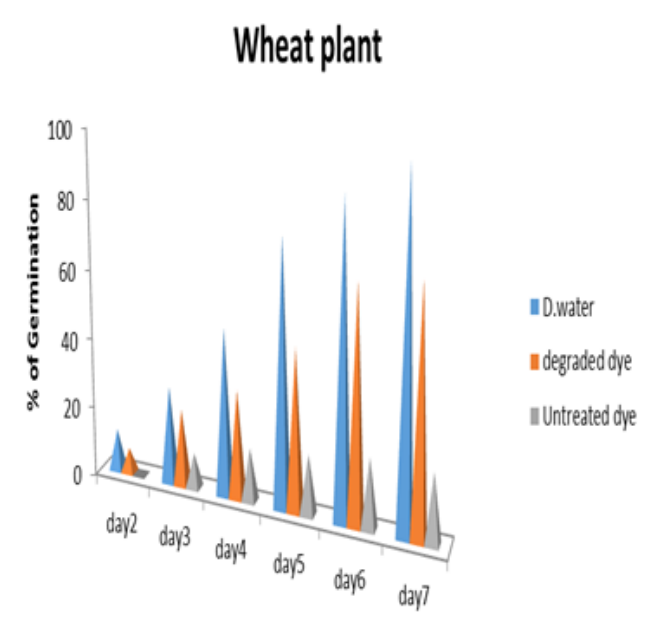

Figure 7. The effect of degraded and control RR1 dye on germination of wheat seedlings. The data indicates the mean of three independent experiments Mean \pm SEM. $\mathrm{p}<0.01$

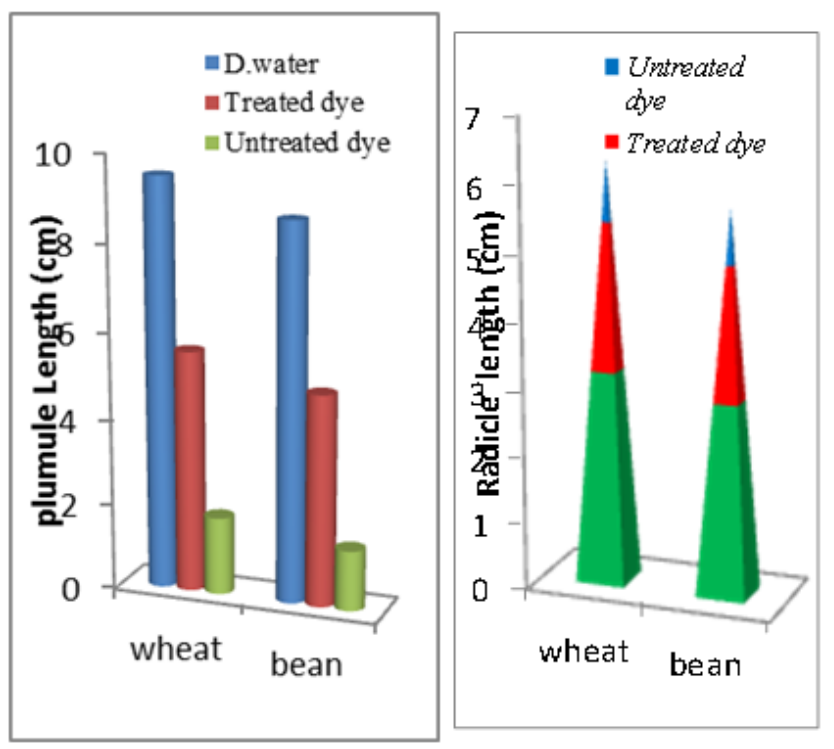

Figure 8. The effect of degraded and control RR1 dye on length of (a) plumule (b) Radicle

Similarly, Phaseolus aureus seeds with degraded RY107 sample showed significant germination i.e. 3 fold rise (Figure 8). The length of plumule and radicle was observed to be significantly affected by both RR1 and RY107 parent azo dyes than their degradative metabolites, indicating less toxic nature of degradation metabolites as compared with parent dyes. The phytotoxic evaluation studies conducted on the germination and early seedling growth of clover, wheat, lettuce and tomato plants showed similar effects $[19,20]$.

\section{Conclusion}

Saccharothrix aerocolonigenes TE5 isolated from the contaminated site is potential for the decolourisation of reactive azo dyes namely RR1, RY107 and RB5. The phytotoxicity studies also revealed that the biodegradation of reactive dyes results into the formation of non-toxic metabolites.

\section{Acknowledgement}

The authors are very grateful to Government of India sponsored DST-FIST \& CURIE Sri Padmavathi Mahila Visvavidyalayam (S.P. Women's University), Tirupati517502, Andhra Pradesh, India for providing Research facilities for successful execution of above research.

\section{References}

[1] Vilaseca, M., Gutie, M.C, Grimau, V.L., Mesas, M.L. and Crespi, M., "Biological Treatment of a Textile Effluent After Electrochemical Oxidation of Reactive Dyes," Water Environ. Res. 82. 176-181. 2010.

[2] Awomeso, J.A., Taiwo, A.M., Gbadebo, A.M. and Adenowo, J.A., "Studies on the pollution of waterbody by textile industry effluents in Lagos, Nigeria," J. Appl. Sci. Environ.Sanit. Sby. 5. 353-359. 2010.

[3] Revenkar, S.M. and Lele, S.S., "Synthetic dye decolourization by white rot fungus, Gandoerma sp. WR-I,” Biresour. Technol. 98. 77-780. 2007.

[4] Easton, J.R., "The dye maker's view. In: Cooper P (ed) Color in dyehouse effluent," Society of Dyers and Colorists, Bradford. 9-21. 1995.

[5] Conneely, A., Smyth, W. F. and McMullan, G., "Metabolism of pthalocyanin textilel dye remazol turquoise blue phenerochaete chrysosporium," FEMS Microbiol Lett. 179. 333-337. 1999.

[6] Zollinger, H., Color Chemistry-Synthesis, Properties and Application of Organic Dyes and Pigment. VCH Publishers, New York. 1987, 92-102.

[7] McMullan, G., Meehan, C., Conneely, A., Kirby, N., Robinson, T., Nigam, P., Banat, I.M., Marchant, R. and Smyth, W.F., "Microbial decolorization and degradation of textile dyes: Mini Review,” Appl. Microbiol. Biotechnol. 56. 81-87. 2001.

[8] Rajeshwari, K., Subashkumar, R. and Vijayaraman, K., "Biodegradation of mixed textile dyes by bacterial strain isolated from dye waste effluent," Res. J. of Env. Toxicology, 5(2). 97-107. 2011. 
[9] Mc Curdy, M.W., Boardman, G.D., Michelsen, D.L. and Woodby, B.M., "Chemical reduction and oxidation combined with biodegradation for the treatment of textile dye," in $46^{\text {th }}$ proc. purdue Industrial waste conf., Lewis publishers, MI, 229-234. 1992.

[10] Xu, Meiying, J., Guo, G., Zeng, X., Zhong and Sun, G., "Decolourization of anthraquinone dye by Shewanella decolouriations S12," Appl. Microbiol. Biotechnol. 71. 246-251. 2006.

[11] Rizwana Parvez, S. and Uma Maheswari Devi, P., "Decolourization of Reactive azo dyes by Aspergillus niger from dying industry effluent" International Journal of Scientific \& Engineering Research, 6. (2). 45-49. 2015.

[12] Sujatha, B., Rashmi, H.K. and Uma Maheswari Devi, P., "Antifungal Activity of Oxylipins Against Papaya Fungal Pathogens," Journal of Experimental Biology and Agricultural Sciences, 1 (2S). 139-145. June - 2013.

[13] Chang, J.S., Chou, Y.P. and Chen, Y.S., "Decolourization of azo dyes with immobilized Pseudomonas luteola," Process Biochem, 36. 757-763. 2001a.

[14] Willmott, N., Guthrie, J. and Nelson, G.,"The biotechnology approach to colour removal from textile effluent," J. Soct. of Dyers and Colourists. 114. 38-41. 1998.
[15] Telke, A., Kalyani, D., Jadhav, J. and Govindwar, S., "Kinetics and mechanism of reactive Red 141 degradation by a bacterial isolate Rhizobium radiobacter MTCC 8161,” Acta Chim. Slov, 55. 320-329. 2008.

[16] Saratale, R.G., Saratale, G.D., Kalyani, D.C., Chang, J.S. and Govindwar, S.P., "Enhanced decolorization and biodegradation of textile azo dye scarlet $\mathrm{R}$ by using developed microbial consortiumGR,” Bioresour. Technol., 100. 2493-2500. 2009b.

[17] Jadhav, S.U., Jadhav, M.U. Kagalkar, A.N. and Govindwar, S.P., "Decolourization of briliant blue G Dye mediated by degradation of the microbial consortium of Galactomyces geotrichum and Bacilus sp.,” J. Chin. Inst. Chem. Engrs., 39. 563. 2008.

[18] Mbuligwe, S.E., "Comparative treatment of dye-rich wastewater in engineered wetland systems (EWSs) vegetated with different plants," Water Research, 39. 271-280, 2005.

[19] Oliveira, D.P., Carneiro, P.A., Sakagami, M.K., Zanoni, M.V.B. and Umbuzeiro, G.A., "Chemical characterization of a dye processing plant effluent - Identification of the mutagenic components," Mutation Research, 626. 135-142. 2007.

[20] Saratale, R.G., Saratale, G.D., Kalyani, D.C., Chang, J.S. and Govindawar, S.P., "Enhanced decolorization and biodegradation of textile azo dye Scarlet $\mathrm{R}$ by using developed microbial consortium-GR,” Bioresource Technology, 100. 2493-2500. 2009. 